\title{
Apiaceae endémicas del Perú
}

\section{Blanca León ${ }^{1,2}$ y Christhian Monsalve ${ }^{1}$}

${ }^{1}$ Museo de Historia Natural, Av. Arenales 1256, Aptdo. 14-0434, Lima 14, Perú.

christhianml@hotmail.com

2 Plant Resources Center, University of Texas at Austin, Austin TX 78712 EE.UU.

blanca.leon@mail.utexas.edu

\section{Resumen}

La familia Apiaceae es reconocida en el Perú por presentar 29 géneros y 88 especies (Brako \& Zarucchi, 1993), básicamente hierbas y subarbustos. En este trabajo reconocemos como endémicos 22 taxones en siete géneros. Un género, Paraselinum, es endémico del Perú. La mayoría de los taxones endémicos ocupan las regiones Desierto Semicálido Costero, Mesoandina y Bosques Muy Húmedos Montanos, entre los 10 y 4400 m de altitud. Ninguna de estas especies está representada en las áreas protegidas.

Palabras claves: Apiaceae, Paraselinum, Perú, endemismo, plantas endémicas.

\section{Abstract}

The Apiaceae are represented in Peru by 29 genera and 88 species (Brako \& Zarucchi, 1993), basically herbs and fruticose plants. Here we recognize 22 endemic taxa in seven genera. One genus, Paraselinum, is endemic to Peru. Most endemic Apiaceae are found in the Subtropical Costal Desert, Mesoandean and Very Humid Montane Forest regions, between 10 and $4400 \mathrm{~m}$ elevation. None of the species have been reported from Peru's protected areas system.

Keywords: Apiaceae, Paraselinum, Peru, endemism, endemic plants.

\section{Arracacia incisa H. Wolff}

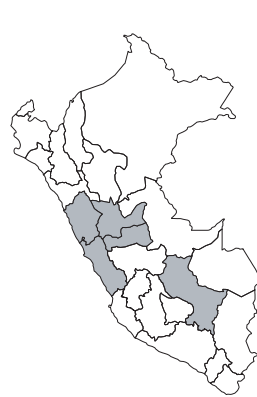

\section{NT} LI, PA. $\mathrm{m}$.
Publicación: Bot. Jahrb. Syst. 40: 305. 1908. Colección tipo: A. Weberbauer 165 Herbarios: B.

Nombre común: Desconocido.

Registro departamental: AN, CU, HU,

Regiones Ecológicas: MA; 3200-3700

SINANPE: Sin registro.

Herbarios peruanos: USM (5).

Observaciones: Subarbusto conocido de varias localidades principalmente en el centro del país, en las cuencas del Rímac y Pativilca Presenta afinidad con otra especie endémica, Arracacia perwiana, pero detalles morfológicos de las inflorescencia distinguen a ambas. Habita ambientes rocosos, escasamente herborizados, los que ocasionalmente son quemados intencionalmente.

\section{Arracacia peruviana (H. Wolff) Constance}

\section{VU, B1ab(iii)}

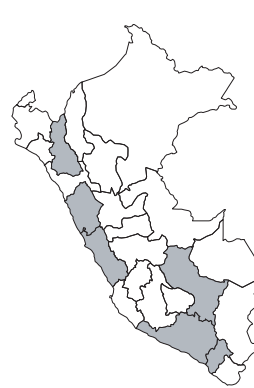

Publicación: Bull. Torrey Bot. Club 76: 45. 1949.

Colección tipo: A. Weberbauer 2748

Herbarios: G.

Nombre común: K'ita rakhacha.

Registro departamental: AN, AY, CA, CU, LI, MO.

Regiones Ecológicas: MA, PAR; 2600$3300 \mathrm{~m}$.

SINANPE: Sin registro.

Herbarios peruanos: CPUN (2), HAO (1), USM (3).

Observaciones: Esta especie herbácea se conoce de poblaciones muy reducidas y aisladas en varias localidades en el país. Las colecciones recientes provienen de 1987, probablemente por tratarse de una especie que se le confunde con Arracacia incisa. Las localidades conocidas para esta especie están en áreas afectadas por la ganadería caprina.

\section{Bowlesia argenticaulis Mathias \& Constance}

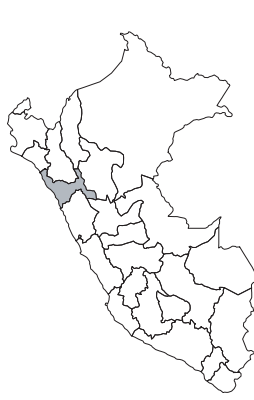

CR, B1a

Publicación: Ann. Naturhist. Mus. Wien 75: 99-101, f. 1. 1971.

Colección tipo: P.C. Hutchison et al. 6261

Herbarios: UC, US.

Nombre común: Desconocido.

Registro departamental: LL.

Regiones Ecológicas: PAR; $3970 \mathrm{~m}$.

SINANPE: Sin registro.

Herbarios peruanos: Ninguno.

Observaciones: Hierba postrada que se conoce solamente del norte del país. Parece tratarse de una especie con probable especificidad a suelos calcáreos. Morfológicamente se caracteriza por los tallos de color plateado y por la presencia de escamas peltadas disectas en el ápice. No ha vuelto, aparentemente, a ser recolectada desde 1964.

\section{Domeykoa amplexicaulis (H. Wolff) Mathias \& Constance}

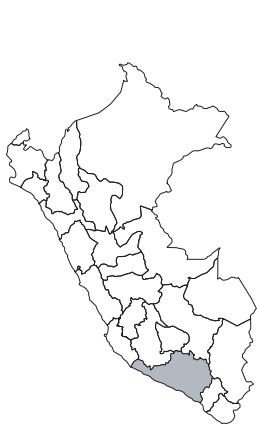

\section{EN, B1ab(iii)}

Publicación: Univ. Calif. Publ. Bot. 33: 175, f. 34. 1962.

Colección tipo: A. Weberbauer 1560

Herbarios: GH.

Nombre común: Desconocido.

Registro departamental: AR.

Regiones Ecológicas: DST, MDE, MA; 50-2600 m.

SINANPE: Sin registro.

Herbarios peruanos: USM (9).

Observaciones: Esta especie es una planta anual conocida solamente del occidente del Departamento de Arequipa. Ha sido recolectada durante la estación invernal cuando hay humedad para la formación de una cobertura vegetal. El hábitat original de esta especie en las lomas costeras de Arequipa está amenazado por la expansión urbana, deterioro ambiental asociado a minería y la ausencia de protección oficial. 


\section{Domeykoa saniculifolia Mathias \& Constance}

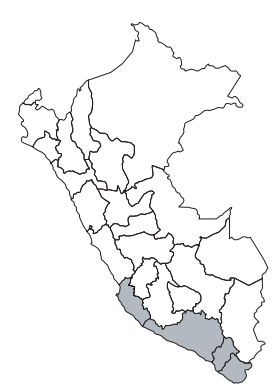

$$
\text { EN, B1ab(iii) }
$$

Publicación: Univ. Calif. Publ. Bot. 33: 179, f. 35. 1962

Colección tipo: R. Ferreyra 12544

Herbarios: UC, US; USM!

Nombre común: Desconocido.

Registro departamental: AR, IC, MO, TA.

Regiones Ecológicas: DST; 500—900 m.

SINANPE: Sin registro.

Herbarios peruanos: USM (isotipo+8).

Observaciones: Esta especie herbácea es una planta generalmente postrada conocida del sur del país. Se conoce de por lo menos cuatro localidades, la recolecta más reciente data de 1958.

\section{Eremocharis confinis I.M. Johnst.}

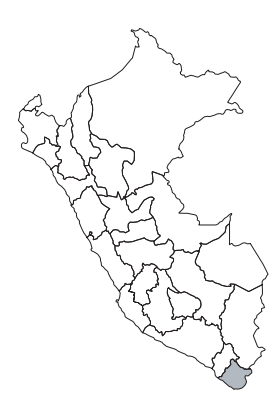

\section{EN, B1a}

Publicación: Contr. Gray Herb. 85: 173 174. 1929.

Colección tipo: A. Weberbauer 7369

Herbarios: F, GH, K, US.

Nombre común: Desconocido.

Registro departamental: TA.

Regiones Ecológicas: MA; 1950—2950 m.

SINANPE: Sin registro.

Herbarios peruanos: USM (1).

Observaciones: Planta de ambientes semixéricos conocida solamente de dos localidades en el sur del país. Aparentemente no ha vuelto a ser recolectada desde 1950. Weberbauer (1945) describió el ambiente de esta especie como dominada por cactáceas columnares y arbustos dispersos.

\section{Eremocharis ferreyrae Mathias \& Constance}

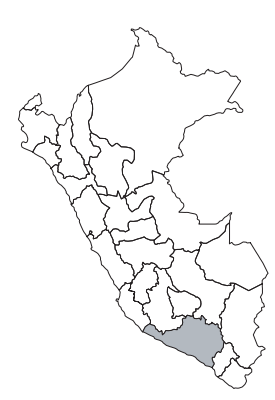

\section{EN, B1ab(iii)}

Publicación: Univ. Calif. Publ. Bot. 33(2): 163, f. 29. 1962.

Colección tipo: R. Ferreyra 6463

Herbarios: UC, US; MOL!, USM!

Nombre común: Desconocido.

Registro departamental: AR.

Regiones Ecológicas: DST; $10-200 \mathrm{~m}$. SINANPE: Sin registro.

Herbarios peruanos: HUT (1), MOL (isotipo), USM (isotipo+4).

Observaciones: Subarbusto conocido de varias localidades en la costa sur del país. Aparentemente no ha vuelto a ser recolectada desde 1961. Cambios climáticos y uso del hábitat de esta especie con fines urbanos podrían ser amenazas a esta especie.

\section{Eremocharis hutchisonii Mathias \& Constance}

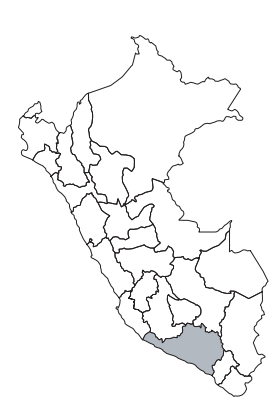

\section{EN, B1a}

Publicación: Univ. Calif. Publ. Bot. 33(2): 161, f. 26. 1962

Colección tipo: P.C. Hutchison 1277

Herbarios: UC, US; USM!

Nombre común: Desconocido.

Registro departamental: AR.

Regiones Ecológicas: MA; $3200 \mathrm{~m}$.

SINANPE: Sin registro.

Herbarios peruanos: USM (isotipo).
Observaciones: Arbusto conocido solamente de dos localidades en la cuenca del Atico. Aparentemente no ha vuelto a ser recolectada desde 1978. Incendios intencionales podrían afectar sus poblaciones.

\section{Eremocharis integrifolia Mathias \& Constance}

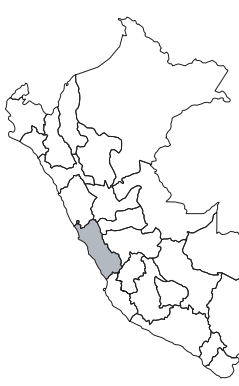

$$
\text { EN, B1ab(iii) }
$$

Publicación: Univ. Calif. Publ. Bot. 33(2): 171, f. 32. 1962.

Colección tipo: E. Asplund 10950

Herbarios: UC, US

Nombre común: Desconocido.

Registro departamental: LI.

Regiones Ecológicas: MA; 2400—2600 $\mathrm{m}$.

SINANPE: Sin registro.

Herbarios peruanos: Ninguno.

Observaciones: Arbusto conocido aparentemente sólo de unas pocas colecciones, todas ellas recolectadas en la cuenca del Rímac. Aparentemente no ha vuelto a ser recolectada desde 1940.

\section{Eremocharis longiramea (H. Wolff) I.M. Johnston}

\section{LC}

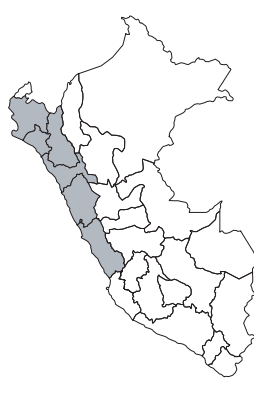

Publicación: Contr. Gray Herb. 85: 174. 1929.

Colección tipo: A. Weberbauer 2993

Herbarios: MOL!.

Nombre común: Naldo.

Registro departamental: AN, CA, LL, LA, LI, PI.

Regiones Ecológicas: MDE, MA; 650$2500 \mathrm{~m}$.

SINANPE: Sin registro.

Herbarios peruanos: HAO (2), MOL (isotipo), USM (15).

Observaciones: Hierba terrestre conocida de varias localidades en la vertiente del Pacífico y de la cuenca del Marañón.

\section{Eremocharis piscoensis Mathias \& Constance}

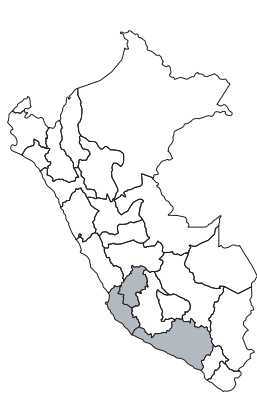

\section{EN, B1ab(iii)}

Publicación: Univ. Calif. Publ. Bot. 33(2): 161, f. 28. 1962.

Colección tipo: W. Rauh \& G. Hirsch P400 Herbarios: UC.

Nombre común: Desconocido.

Registro departamental: AR, HV, IC. Regiones Ecológicas: DST, MDE; 550$2000 \mathrm{~m}$.

SINANPE: Sin registro.

Herbarios peruanos: USM (1).

Observaciones: Arbusto conocido de unas pocas localidades en la costa y vertiente del Pacífico del centro del país. Esta especie se conoce de ambientes de lomas y laderas rocosas con vegetación efímera. 


\section{Eremocharis tripartita (H. Wolff) Mathias \& Constance}

\section{NT}

Publicación: Univ. Calif. Publ. Bot. 33: 169, f. 31. 1962.

Colección tipo: A. Weberbauer 3909

Herbarios: MOL!

Nombre común: Neldo.

Registro departamental: CA, LL.

Regiones Ecológicas: MDE, MA; 650$2800 \mathrm{~m}$.

SINANPE: Sin registro.

Herbarios peruanos: CPUN (2), HAO (4), MOL (isotipo), USM (2).

Observaciones: Planta perenne conocida de la cuenca del Chicama en la vertiente del Pacífico y del valle del Marañón. Habita ambientes escarpados y xéricos.

\section{Eremocharis triradiata (H. Wolff) I.M. Johnst.}

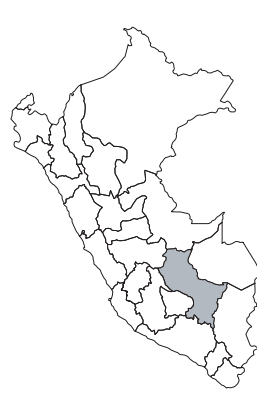

\section{VU, B1a}

Publicación: Contr. Gray Herb. 85: 174. 1929.

Colección tipo: A. Weberbauer 4934

Herbarios: B.

Nombre común: Desconocido.

Registro departamental: CU.

Regiones Ecológicas: MA; 2950—3780 $\mathrm{m}$.

SINANPE: Sin registro.

Herbarios peruanos: USM (4).

Observaciones: Hierba anual que es conocida de varias colecciones realizadas en la cuenca del Urubamba y Cosñipata.

\section{Hydrocotyle bonplandii A. Rich. var. hirtipes Mathias}

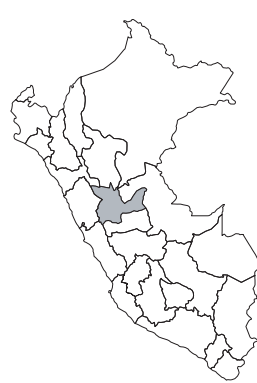

\section{NE}

Publicación: Brittonia 2(3): 233. 1936. Colección tipo: J.F. Macbride 4236

Herbarios: F, US.

Nombre común: Desconocido.

Registro departamental: HU.

Regiones Ecológicas: BMHP; $1200 \mathrm{~m}$.

SINANPE: Sin registro.

Herbarios peruanos: Ninguno.

Observaciones: Jørgensen \& León Yánez (1999) consideran a la especie para Ecuador sin categorías infraespecificas. Se requiere aclarar el estatus taxonómico de esta variedad.

\section{Hydrocotyle dahlgrenii Rose \& J.F. Macbr.}

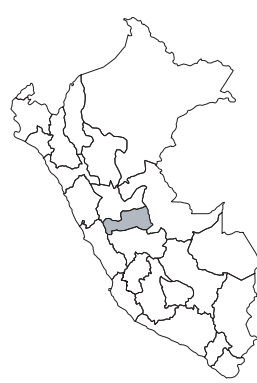

\section{CR, B1a}

Publicación: Field Mus. Nat. Hist., Bot. Ser. 11(1): 32-33. 1931.

Colección tipo: J.F. Macbride 4776

Herbarios: F.

Nombre común: Desconocido.

Registro departamental: PA.

Regiones Ecológicas: BMHP; $1050 \mathrm{~m}$.

SINANPE: Sin registro.

Herbarios peruanos: Ninguno.

Observaciones: Hierba conocida solamente de la colección tipo, una planta recolectada en 1923 de la cuenca del Pozuzo, un tributario del Pachitea. La localidad tipo fue registrada por error para el Departamento de Huánuco.

\section{Hydrocotyle globiflora Ruiz \& Pav.}

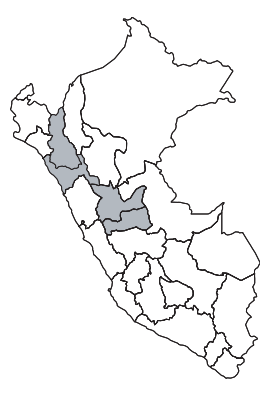

EN, B1a

Publicación: Fl. Peruv. 3: 25, t. 247, f.a. 1802.

Colección tipo: H. Ruiz \& J. Pavón s.n.

Herbarios: MA.

Nombre común: Desconocido.

Registro departamental: CA, HU, PA.

Regiones Ecológicas: BMHP; 1000$1500 \mathrm{~m}$.

SINANPE: Sin registro.

Herbarios peruanos: USM (2).

Observaciones: Hierba postrada conocida de unas cuatro localidades en el centro del país. El ejemplar tipo fue recolectado en el siglo XVIII, en la cuenca del Huallaga. Esta especie está escasamente representada en los herbarios peruanos.

\section{Hydrocotyle gracilis Ruiz \& Pav.}

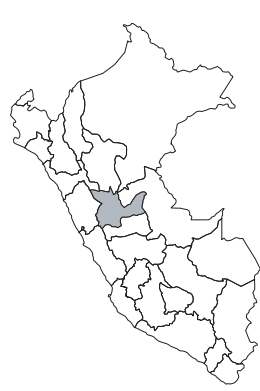

DD

Publicación: Fl. Peruv. 3: 26, t. 247, f.b. 1802.

Colección tipo: H. Ruiz \& J. Pavón s.n.

Herbarios: MA.

Nombre común: Desconocido.

Registro departamental: HU.

Regiones Ecológicas: Sin datos; altitud desconocida.

SINANPE: Sin registro.

Herbarios peruanos: Ninguno.

Observaciones: Hierba conocida aparentemente sólo de la colección tipo, una planta recolectada en el siglo XVIII de la cuenca del Huallaga, en matorrales ribereños.

\section{Hydrocotyle longipes Mathias \& Killip}

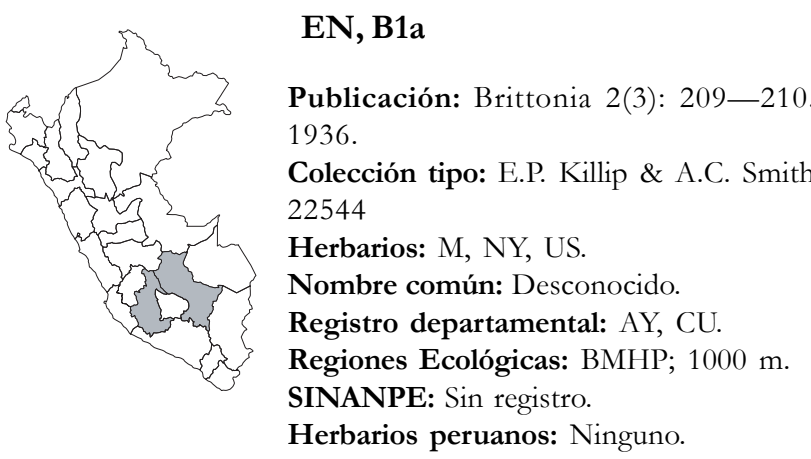

Observaciones: Hierba terrestre conocida de los bosques húmedos del sur-oriente del país. El ejemplar tipo proviene de la cuenca del Apurímac y fue recolectado en 1929; esta localidad requiere de estudios florísticos.

\section{Hydrocotyle sagasteguii Constance \& M.O. Dillon}

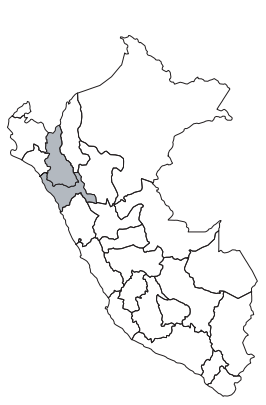

Publicación: Brittonia 42(4): 257-259, f. 1.1990 .

Colección tipo: M.O. Dillon \& A. Sagástegui A. 4413

Herbarios: MO; HUT.

Nombre común: Desconocido.

Registro departamental: CA, LL.

Regiones Ecológicas: MA; 1500-2000 m.

SINANPE: Sin registro.

Herbarios peruanos: HUT(isotipo). 
Observaciones: Hierba descrita de una planta recolectada en 1986, en la cuenca del Zaña. Esta especie habita los fragmentos de bosque perennifolios de la vertiente del Pacífico, los cuales están muy amenazados por la deforestación.

\section{Hydrocotyle vestita Mathias \& Killip}

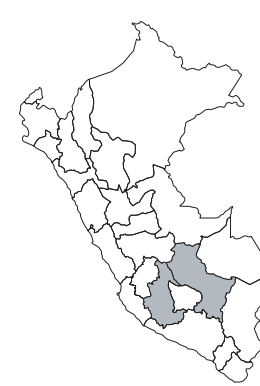

\section{EN, B1ab(iii)}

Publicación: Brittonia 2(3): 222-223. 1936.

Colección tipo: E.P. Killip \& A.C. Smith 22759

Herbarios: M, NY, US.

Nombre común: Desconocido.

Registro departamental: AY, CU.

Regiones Ecológicas: BMHP; $800 \mathrm{~m}$.

SINANPE: Sin registro.

Herbarios peruanos: Ninguno.

Observaciones: Hierba conocida aparentemente sólo del sur del país. La colección tipo fue recolectada en 1929 de la cuenca del Apurímac. Esta localidad ha sido escasamente herborizada.

\section{Niphogeton stricta (H. Wolff) Mathias \& Constance}

\section{VU}

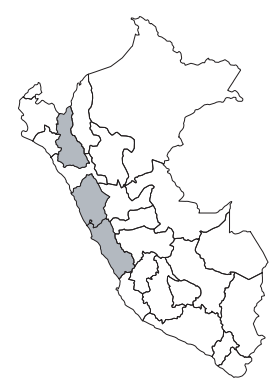

Publicación: Univ. Calif. Publ. Bot. 23(9): 419. 1951.

Colección tipo: A. Weberbauer 3153

Herbarios: MOL!

Nombre común: Desconocido.

Registro departamental: AN, CA, LI.

Regiones Ecológicas: PSH, PAR; 3450$3900 \mathrm{~m}$.

SINANPE: Sin registro.

Herbarios peruanos: CPUN (3), MOL (isotipo), USM (2).

Observaciones: Hierba conocida de varias localidades en el norte y centro en la vertiente del Pacífico. Habita matorrales y áreas ecotonales entre pajonales y bosques.

\section{Paraselinum weberbaueri $\mathrm{H}$. Wolff}

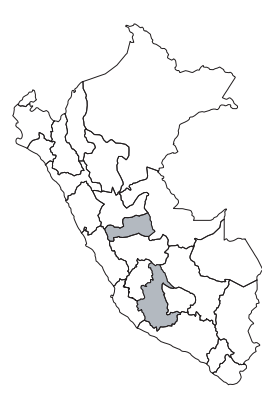

\section{EN, B1a}

Publicación: Repert. Spec. Nov. Regni Veg. 17: 174. 1921.

Colección tipo: A. Weberbauer 5471

Herbarios: F.

Nombre común: Desconocido.

Registro departamental: AY, PA.

Regiones Ecológicas: MA; 3500—4400 $\mathrm{m}$.

SINANPE: Sin registro.

Herbarios peruanos: Ninguno.

Observaciones: Esta especie perenne es la única representante de este género también endémico y fue descrita de una planta recolectada en 1910, en el departamento de Ayacucho. Un ejemplar adicional es conocido de la Cordillera de Raura, recolectado en la década de 1950. 